\title{
Varia
}

\section{The Directive on Preventing and Combatting Trafficking in Human Beings and the Principles Governing European Criminal Policy - A Critical Evaluation}

\author{
Helmut Satzger, Frank Zimmermann and Georg Langheld ${ }^{1}$
}

\section{Introduction}

The fight against trafficking in human beings has been on the agenda of the European institutions for several years. In 2011, a new Directive ${ }^{2}$ (hereinafter: the Directive) was adopted for this purpose, repealing a Framework Decision of $2002^{3}$. While the scope of this Directive extends to taking certain measures for protecting the victims of human trafficking ${ }^{4}$, this brief ${ }^{5}$ evaluation will focus on the question as to whether this new instrument complies with fundamental principles of criminal policy. Such guidelines have - in particular - been elaborated in the Manifesto on European Criminal Policy, which was published by the European Criminal Policy Initiative (ECPI) in $2009,{ }^{6}$ and have since also been adopted by the European institutions. ${ }^{7}$

\section{Basic features of the directive and the requirement of a legal interest worthy of protection}

As the structure of the Directive is very complex, it appears worthwhile to first take a closer look at the elements of the crime as stipulated by the Directive. As objective elements, Art. 2 (1) of the Directive ${ }^{8}$ requires that one of several acts ("recruitment, transportation, transfer, harbouring or reception of persons") be committed by using one of several coercives ("by means of the threat or use of force or other forms of coercion, of abduction, of fraud, of deception, of the abuse of

\footnotetext{
${ }^{1}$ Prof. Dr. Helmut Satzger holds the Chair of German, European and International Criminal Law, Criminal Procedure as well as Business Criminal Law at the Ludwig-Maximilians-Universität München, Germany and is a member of the European Criminal Policy Initiative. Frank Zimmermann and Georg Langheld work as his research assistants at the LMU and participate in the ECPI's projects.

${ }^{2}$ Directive 2011/36/EU, OJ 2011 No. L 101, p. 1. On this instrument cf. Kaiafa-Gbandi, EuCLR 2011, 7, 14 and 32.

${ }^{3}$ Council Framework Decision 2002/629/JHA, OJ 2002 No. L 203, p. 1.

${ }^{4}$ Cf. Villacampa Estiarte, EuCLR 2012, 291 et seq.

${ }^{5}$ A comprehensive and more detailed version of this review will be published on the internet: see www.crimpol. eu.

${ }^{6}$ ZIS 2009, 707 et seq. as amended in EuCLR 2011, 86 et seq.; cf. also www.crimpol.eu.

7 Council Document No. 16542/09. COM(2011) 573; cf. Reding, EuCLR 2011, 1 et seq. Report A7-0144/2012 of the European Parliament, available on http://www.europarl.europa.eu.

${ }^{8}$ All references to legal provisions hereinafter shall refer to the Directive (fn. 1) unless explicitly stated otherwise.
} 
power or of a position of vulnerability or of the giving or receiving of payments or benefits to achieve the consent of a person having control over another person"). Art. 2 (1) further introduces subjective elements of crime by stipulating that the act be committed and that the coercive be used intentionally and for the purpose of exploitation. To what the term "purpose of exploitation" refers is clarified to some extent by Art. 2 (3). The term "exploitation" shall include sexual exploitation and forced labour or services, in particular. This is where the Directive differs most strikingly from the repealed Framework Decision (at least as far as substantive criminal law is concerned): "begging" is explicitly mentioned as a form of forced labour and the exploitation of criminal activities as well as the removal of organs shall now be covered by the notion of exploitation in Art. 2 (1). Pursuant to Art. 3 , "inciting, aiding and abetting or attempting to commit an offence" of human trafficking shall likewise be punished by the Member States. As regards the type and level of sanctions, Art. 4 requires the national legislatures to provide for a maximum penalty of not less than five years imprisonment. If the offence is committed under certain aggravating circumstances, Art. 4 (2) calls for a minimum maximum sanction of ten years imprisonment.

\section{Legal interests protected by the Directive}

Two different interests protected by the Directive may be distinguished: As to the use of coercives, Art. 2 aims to protect the liberty and physical integrity ("use of force") of any potential victim. Since these interests are embodied in the objective elements of crime, the Directive does not introduce criminal liability unless they are actually harmed. By contrast, the element "for the purpose of exploitation" is a merely subjective one. It aims to protect a variety of interests: the alternative "sexual exploitation" protects the sexual self-determination; forced labour or services, slavery or practices similar to slavery and servitude concern the individual liberty of a victim as well as the victim's ability to work. If the act is committed in order to remove an organ, the victim's physical integrity will also be affected. Since Art. 2 (1) does not require that a perpetrator actually exploits a victim, the Directive aims to establish criminal liability where these various interests are merely put at risk of being violated. As a consequence, the statutory offences which need to be enacted by the Member States in order to implement the Directive will serve a double purpose: they will protect citizens from the actual commitment of coercive acts on the one hand and from any corresponding danger of harm to further legal interests such as their sexual self-determination, individual liberty, ability to work and physical integrity, on the other hand.

\section{Points of criticism as to the protected interest: Art. 2 (4) and (5)}

Although the legal interests identified above, are - generally speaking - legitimate grounds for criminal legislation ${ }^{9}$, the EU legislator exceeds what is necessary to

\footnotetext{
${ }^{9}$ Cf. also the critical view taken by Böse, EuCLR 2011, 35, 37 et seq.
} 
ensure their protection: First, according to Art. 2 (4), the consent of the victim to the exploitation shall be irrelevant where any of the coercives mentioned in Art. 2 (1) have been used. Indeed, the victim will normally only agree to an infringement of liberty when under the influence of a coercive. This is why Art. 2 (4) is a necessary and welcome provision. It may, however, be interpreted in a way that strips the victim's consent of any relevance even if the coercive situation does not persist. For instance, there may be cases in which the victim sees through the perpetrator's deceptive intentions and plays along. It is not convincing to extend criminal protection to these cases as well. The legal interest to protect individuals from infringements on their liberty is not at stake as the "victim" then acts according to its own free will.

Secondly, according to Art. 2 (5), the criminal conduct referred to in Art. 2 (1) shall be punishable regardless of the use of coercives if a child is involved as a victim. This waiver is not necessary and entails problematic consequences: if a child, i. e. a person under the age of 18 years (cf. Art. 2 (6)) is actually more vulnerable in a specific situation than an adult, the objective elements of crime as stipulated in Art. 2 (1) - including the requirement of coercive measures - will easily be met. It is hardly conceivable that a child should be willing to surrender itself to the perpetrator's will without the latter taking advantage of the child's inexperience, using ,other forms of coercion“ or deception. If at all, this may be a realistic scenario for a developed child close to the age of 18 years. In this case, however, it remains unclear why this should be treated as human trafficking: if on the one hand the intended conduct meets the requirements of another statutory offence, such as the sexual exploitation and prostitution of minors or coercion, these offences suffice to protect the interests of the child. If on the other hand the intended conduct is not a criminal offence under other provisions, there is no obvious reason why the recruitment, transportation etc. need to be punished as trafficking in human beings. It should also be added that the elements of the crime as modified by Art. 2 (5) of the Directive do not correspond to the typical image of trafficking in human beings since they dispense with the victim's concrete position of vulnerability. The elements of the crime therefore run the risk of missing the purpose of the Directive in exceptional cases, while at the same time reducing the definiteness of the statutory offence as a whole.

Of course, it could be argued that the Council of Europe's Warsaw Convention on Action Against Trafficking in Human Beings contains (almost) identical provisions. ${ }^{10}$ But this does not justify simply copying and pasting them into an EU instrument: a Directive creates much more extensive obligations as it does not require ratification by national parliaments and its implementation can be controlled by means of an infringement proceeding. Furthermore, the EU legislator has the possibility to impose a minimum of criminal sanctions. For these reasons it must pay full respect to fundamental principles of criminal policy irrespective of what other international institutions have adopted.

\footnotetext{
${ }^{10}$ CETS No. 197, of 15 May 2005, entered into force on 1 February 2008 (Art. 4 (b) and (c)).
} 


\section{Conflicts with the ultima ratio principle}

In order to fully comply with the ultima ratio principle, which can be derived from the principle of proportionality enshrined in Art. 5 (4) TEU, ${ }^{11}$ the European legislator has to look for alternative measures not involving criminal law in the first place (1.). Should alternative measures not be considered sufficient, the legislator has to give reasons for this conclusion (2.). In any case, the legislator needs to demonstrate that it is proportionate to resort to criminal law, notwithstanding its most serious consequences for the individual (3.).

\section{Alternative measures for sufficiently protecting legal interests}

If and to what extent alternative, non-criminal-law measures may suffice depends on how seriously the respective acts affect the victim's legal interests. In particular, due consideration must be given to the question of whether there are alternatives to the tendency of requiring punishment well in advance of an actual violation of the protected legal interests ${ }^{12}$, thereby establishing the perpetrator's criminal liability far before actual harm is done. Art. 2 (1) simply requires the perpetrator to act for the purpose of exploitation and not to actually exploit the victim. The elements of the crime therefore apply to conduct which is only intended to make such exploitation possible. What is more: since the attempt of these offences shall also be punishable, the perpetrator runs the risk of criminal liability at an even earlier stage. It should have been analysed whether it is possible to exhaust alternative means for the protection of the interests at stake at this early stage.

However, there is a need to distinguish between the various alternative acts of the crime: As regards the transportation, transfer, harbouring or reception of persons, the victim will usually find itself within the perpetrator's sphere of influence who is then in the position to virtually exert power and to progress to exploiting the victim. This is abundantly clear for certain means of coercion like the exchanging or transferring of control over persons. To this extent, other measures for protecting the victim are not apparent. As to the act of recruitment, this is different. This alternative applies to cases in which the victim engages with the perpetrator due to an offer by the latter. At this early stage, the perpetrator is not normally in a position of power which is comparable to the one implied by the other situations covered. This alternative advances criminal liability even further. As a consequence, alternatives to criminal punishment - such as broad information campaigns in both, the countries of origin and the target countries - must duly be regarded. Such measures may be costly. In order to combat trafficking in human beings effectively, however, Member States must not limit themselves to introducing or to aggravating criminal measures which seemingly do not involve any additional costs. Criminal sanctions do not take the bull by the horns. They only take effect once the offence has been

\footnotetext{
${ }^{11}$ ECPI, ZIS 2009, 707 and EuCLR 2011, 86, 88. Cf. Böse, EuCLR 2011, 35,39 et seq.

${ }^{12} \mathrm{Cf}$. the analysis of the elements of the crime supra II.1.
} 
committed and should therefore only accompany and complement measures aiming at the roots of the problem.

\section{Failure to demonstrate the lack of effectiveness of alternative mea- sures}

The EU legislator presupposes that there is a necessity for criminal sanctions to counter trafficking in human beings. In this regard, there seems to be consensus among the Member States which is illustrated by the fact that the Directive (or the previous Framework Decision respectively) is based on the requirements set up by other international legal instruments. ${ }^{13}$ But once again, this cannot discharge the EU legislator of its duty to scrutinise as to whether every act that it wishes to define as human trafficking really needs to be punished (especially considering the extension of criminal liability) or whether alternative means would be sufficient. It must be mentioned as a positive aspect of this Directive that the EU legislator acknowledges the need for a comprehensive approach towards combatting trafficking in human beings which does not exclusively resort to criminal law but also incorporates preventive measures. ${ }^{14}$ However, the preventive measures called for in Art. 18 of the Directive are not precise at all, which means that it will be difficult to assess whether the steps taken by the Member States meet the requirements set for them. A detailed contemplation as to whether the prescription of certain acts in the Directive could be replaced by non-criminal-law measures is nowhere to be found in the preparatory works.

Furthermore, the Directive lacks reasoning for one elementary question: as the preparatory works ${ }^{15}$ acknowledge, there is no reliable empirical data as to the extent of human trafficking within the Union. Without these data, however, it is impossible to assess to what extent legislative steps are truly necessary. The number of criminal proceedings dealing with offences of human trafficking is not very meaningful and the low number of convictions does not prove anything: it would be necessary to know whether a criminal proceeding could not be conducted due to shortcomings of the Member States' criminal laws. The EU legislator should have conducted a more thorough analysis in this regard.

\section{Do the proscribed types of conduct indeed call for criminal sanctions as a last resort?}

The elements of the crime as stipulated in Art. 2 cover a number of alternatives. As to the reasoning for their penalisation, the Directive does not distinguish between them. This may be due to the fact that the repealed Framework Decision

\footnotetext{
${ }^{13}$ See, in particular, the Protocol to Prevent, Suppress and Punish Trafficking in Persons Especially Women and Children, supplementing the United Nations Convention against Transnational Organized Crime, United Nations Treaties Service, Vol. 2237, p. 319; Doc.A/55/383 and Council of Europe Convention on Action against Trafficking in Human Beings, CETS No. 197, of 15 May 2005, which entered into force on 1 February 2008.

${ }^{14}$ Cf. Villacampa Estiarte, EuCLR 2012, 291, 305 et seq.

${ }^{15}$ SEC (2009) 358 final, p. 7.
} 
had already contained mostly identical requirements for criminal liability. A thorough and detailed reasoning should however have been provided for the newly incorporated aspects of the "intent of exploitation". 16 The preparatory works simply refer to other international legal instruments which also aim to impose criminal sanctions. Irrespective of the obligations they impose, these instruments neither give the EU legislator carte blanche, nor do they justify the simple copying of the relevant provisions and their inconsiderate insertion into the Directive in order to make them legally binding without pursuing a consistent European criminal policy. This may still be acceptable for "removal of organs" because such conduct is among the most upsetting offences imaginable. But especially with regard to the exploitation of criminal offences, a closer look at the legal justification would have been necessary (cf. infra VII.1.).

\section{Conflicts with the principle of guilt}

The principle of guilt, which is fundamental and which can also be regarded as a corollary of the proportionality requirement, primarily obliges the legislator to adapt the type and level of sanctions to the severity of the perpetration. ${ }^{17}$ It must be (positively) noted that the Directive distinguishes between "normal" and aggravated cases by calling for higher minimum maximum penalties in the latter ones. Nevertheless, the Directive treats acts of a very different severity the same way and thus does not fully respect the principle of guilt:

As opposed to the repealed Framework Decision, the Directive does proscribe different minimum maximum penalties for perpetrators on the one hand (Art. 4 (1) to (3)) and for participants on the other (Art. 4 (4)). ${ }^{18}$ However, it does not do so with regard to main perpetrators and subordinates. Instead, Art. 2 (1) establishes that several acts that would usually be considered as forms of aiding and abetting shall be made criminal offences of their own. What is more, the Directive only requires the respective acts to be committed "for the purpose of exploitation" and does not require that the perpetrator intends to exploit the victim personally. For example: someone who transports a victim to another place is treated in exactly the same way as someone else who takes control of and exploits the person for his or her own personal benefit. A subordinate driver, who does not seek a substantial material gain from the act and does not exert force upon the victim, would consequently be confronted with the same minimum maximum penalty as the person controlling the actual "selling" of human beings and benefiting from it.

This also applies to the act of recruitment. As pointed out above (supra III.1.), this alternative aims to establish criminal liability well before the act of exploitation takes

\footnotetext{
${ }^{16}$ Including the removal of organs and exploitation of criminal activities; the mention of begging is only declaratory since begging is just one manifestation of forced services.

${ }^{17}$ ECPI, ZIS 2009, 707 et seq. and EuCLR 2011,

${ }^{18}$ In the Framework Decision, Art. 3 (1) had stipulated the same sanctions for perpetrators and aiders and abettors, see the criticism by the ECPI, ZIS 2009, 712 et seq. and EuCLR 2011, 86, 97.
} 
place and even well before the victim finds himself/herself in an inferior position to the perpetrator. For example: if the victim's consent to being transported to another country is obtained by deception, this may result in criminal liability regardless of whether the transport has already taken place. This situation is not comparable to a case in which the victim is actually abducted from home by force. Consider the following example: if the victim decides to go "voluntarily" due to deception but misses the arranged time of departure, the Directive would classify this as a case of human trafficking with the same minimum maximum penalty as if the victim had been forced to go abroad.

In a similar way, the list of coercives includes the "giving or receiving of payments or benefits to achieve the consent of a person having control over another person". Under this alternative, even minor participants such as couriers become perpetrators and are treated in the same way as those who actually use force.

Although the distinction of several degrees of severity drawn in Art. 4 (1) and (2) is welcome, the aggravated cases enumerated in Art. 4 (2) do not fully respect the requirement to punish in accordance with the individual's guilt. In particular, the aggravating circumstance of committing the offence against a victim who is particularly vulnerable (cf Art. 4 (2) (a)) does not in any way exceed the basic elements of the crime set forth in Art. 2 (1). The general definition of human trafficking already mentions the abuse of a position of vulnerability as one of several coercives. Thus, a perpetrator who abuses a victim's position of vulnerability may meet the basic elements of the crime and at the same time be held accountable for an aggravating circumstance which results in the double minimum maximum penalty. This problem is exacerbated by the lack of definiteness as to the element of "vulnerability" (see infra V.1.).

Furthermore, the mere fact that an offence of human trafficking is committed within the framework of a criminal organisation (lit. b) is not necessarily as severe as endangering the life of the victim (lit. c) and thus should not entail the same minimum maximum penalty.

Unfortunately, these shortcomings, especially the equal treatment of all alternative acts, are not discussed or explained by the EU legislator. Furthermore, the EU legislator reveals a problematic attitude towards criminal policy in Recital No. 12 according to which the levels of penalties reflect the "growing concern" among Member States: mere concerns should never be regarded as a sufficient justification for a certain level of criminal sanctions (nor for the introduction of criminal punishment at all).

\section{Conflicts with the principle of legality (nullum crimen sine lege)}

\section{Full harmonisation}

The principle of legality must be respected by the EU legislator. It must exert particular caution as to phrasing the elements of crime precisely, especially with regard to provisions which do not provide the Member States with any leeway for 
implementation. ${ }^{19}$ This means that the objective and subjective elements of crime as well as the sanctions which could be imposed must be sufficiently foreseeable. The Directive imposes on the Member States an extensive obligation to punish. The alternative acts as stipulated in Art. 2 (1) overlap and aim to describe the whole process of transporting a person and to incriminate all actions in this regard completely. The enumeration of possible means of coercion is even more comprehensive: it is virtually impossible to imagine a conduct directed at influencing the will of a person which is not covered. The Member States are therefore not left with any margin of discretion in this regard. To this extent, the Directive must, consequently, meet a high standard of clarity to which it does not live up.

Especially two elements of the offence do not allow the citizen to sufficiently foresee his or her criminal liability: "abuse of power" and "abuse of a position of vulnerability". These two elements can be seen as two faces of the same coin since they both convey a notion of a power divide: one of the persons concerned must be superior to the other. This is why both terms face the same criticism as to their precision: it is unclear how to identify a sufficient degree of superiority at which the superior must give due regard to the interests of the inferior. But what is, for instance, a sufficient economic divide between two people in order to result in an "abuse of power"?

The definition of vulnerability in Art. 2 (2) of the Directive does not contribute to the exactness of these terms. To the contrary, it adds to the lack of definiteness since the assessment of vulnerability depends on whether the victim has no real or acceptable alternative. If one additionally takes into consideration the German wording ("keine für sie annehmbare andere Möglichkeit", i. e. no alternative acceptable for the victim), the Directive can be interpreted to oblige national legislators to determine vulnerability from the victim's perspective. As an element of the crime, such a criterion would be far too indefinite since one would have to resort to individual factors which could not be determined by applying an abstract standard. As a consequence, this element may even extend to cases in which a person could be expected to withstand a situation of pressure from an objective point of view. In order to ensure a certain standard of definiteness, the two elements mentioned above would have had to be phrased more clearly.

\section{Possibility to adopt implementing legislation in line with the lex certa requirement}

Even to the extent to which the Directive does not aim at a full harmonisation of the Member States' criminal laws, single elements prescribed by the European legislator may be too vague to be implemented into national criminal law provisions without infringing upon the lex certa principle (which is a constitutional guarantee in most legal orders). Most of the elements of crime in this Directive are definite enough, so that the Member States can avoid such conflicts by simply transposing

${ }^{19}$ ECPI, ZIS 2009, 707, 708 and EuCLR 2011, 86, 89. 
them literally. However, some terms do cause conflicts with the principle of legality for the national legislators.

Does, for instance, the alternative conduct of "recruitment" require that the perpetrator's efforts to convince the victim have to be successful or is it sufficient that the offender approaches the victim and begins to influence him or her?

Art. 4 (2) (d) is another particularly problematic provision as it prescribes completely open and vague criteria for augmenting the minimum maximum penalties: "serious violence" and "particularly serious harm". The Directive does not define these terms. National legislators may of course attempt to clarify their meanings, e. g. by deciding whether the term "particularly serious harm" should also extend to psychological or financial damages. By providing such a clarification, however, the Member States risk failing to implement the Directive correctly - especially if the Court of Justice of the European Union should opt for a broader interpretation.

As to the sanctions, Member States are left with a broader margin of discretion for promoting their own criminal policies since the Directive by relying on "minimum maximum sentences" only obliges them to adjust their maximum penalties to the minimum prescribed. Art. 4 (3), which makes the committing of a crime by an official an aggravating circumstance, leaves it up to the national legislators to decide whether this aspect should be considered when determining the sanction in each particular case or whether they prefer to enact a statute providing for higher penalties, while ensuring the conformity to the principle of definiteness themselves.

\section{Conflicts with the principle of subsidiarity}

With regard to respecting the principle of subsidiarity, the EU legislator basically has to answer why criminal law measures at the Member States' level are not sufficient. ${ }^{20}$ Since trafficking in human beings in general appears as a cross-border phenomenon, the investigation and prosecution of these crimes depends heavily on the cooperation of the Member States concerned, which is enhanced by harmonised criminal statutes. A satisfactory level of harmonisation cannot be achieved by national legislators on their own - even if they should choose to cooperate closely. But this assessment does not mean that the crime of trafficking in human beings always involves several Member States. Each of the punishable acts pursuant to Art. 2 (1) can be carried out within the jurisdiction of a single Member State as well, although cross-border implications seem to be a typical element. Other international instruments upon which the Member States build their cooperation to fight trafficking in human beings more effectively (cf. UN Protocol of $2000^{21}$ and the Warsaw Convention of the Council of Europe ${ }^{22}$ ) may serve as a hint for the

\footnotetext{
${ }^{20}$ Cf. Asp, EuCLR 2011, 44 et seq.

${ }^{21}$ Protocol to Prevent, Suppress and Punish Trafficking in Persons Especially Women and Children, supplementing the United Nations Convention against Transnational Organized Crime, United Nations Treaties Service, Vol. 2237, p. 319; Doc.A/55/383.

22 Council of Europe Convention on Action against Trafficking in Human Beings, CETS No. 197, of 15 May 2005, which entered into force on 1 February 2008.
} 
need to find a common solution at the European level. It is striking, though, that the UN Protocol limits its scope of application to cross-border cases. ${ }^{23}$ Such a limitation would have been conceivable in the Directive as well because it is precisely the aspect of "cross-border trading" that makes trafficking in human beings a typically international crime. However, the Directive equally applies to forms of conduct that lack a transnational character. For instance, it is difficult to find a crossborder element in a case where the perpetrator and the victim share the same nationality and the recruitment takes place in their home country. Only to the extent that the Directive covers the actual trading of human beings, the assumption that the instrument is in line with the principle of subsidiarity can be regarded as justified. Unfortunately, the EU legislator did not make any efforts to explain why this requirement is also met with regard to the other alternatives of the definition. By contrast, it has founded its reasoning with regard to the principle of subsidiarity almost exclusively on the general cross-border implications of this crime phenomenon. Furthermore, the international character of this crime should have been based on intensive recourse to statistical evidence which - regrettably - has not been collected.

\section{Conflicts with the principle of coherence}

\section{1. "Vertical" coherence - implications for domestic criminal law sys- tems}

The requirement of vertical coherence stipulates that European harmonisation instruments - although by definition influencing the domestic legal systems - must respect the fundamental structures and characters of the Member States' criminal justice systems, which are part of their national identities (Art. 4 (2) TEU). ${ }^{24}$ These national criminal justice systems might otherwise become inconsistent and even contradictory, a situation that can easily amount to a loss of acceptance and thus a weakening of the system's efficiency. ${ }^{25}$ In the case of this Directive, the act of recruitment, which has already been criticised above in a different context (cf. in particular III.1, IV. and VI.), may cause severe conflicts with the basic concepts of national criminal law - especially those dealing with the participation in crimes. For example:

Whosoever recruits someone to commit a crime by means of deception would be liable as an indirect perpetrator of the crime in Germany. What is more, the Directive does not require that the situation of coercion persists at the time of the (intended) commitment of the crime by the victim. The perpetrator would then be liable for trafficking in human beings even in cases in which the victim chooses to take sides with the perpetrator.

\footnotetext{
${ }^{23}$ Cf. Art. 4 of said Protocol (fn. 20). Art. 2 of the Warsaw Convention, however, extends the scope of its application to national and transnational cases.

${ }^{24}$ Cf. Asp, EuCLR 2011, 44 et seq.

${ }^{25}$ ECPI, ZIS 2009, 707, 709 and EuCLR 2011, 86, 91.
} 
Moreover, the conflict with the general concepts on participation in crimes becomes most obvious in cases where a child shall be recruited for the purpose of exploiting criminal offences that it is supposed to commit. For these cases, the Member States may not require the use of coercive means to establish criminal liability. If, for example, a 20-year old manages to persuade a 17-year old friend to commit a theft or burglary for him, the mere act of persuasion will make him criminally liable for trafficking in human beings: he will be considered to have recruited a child for the purpose of exploiting him/her for criminal activities. Since the Directive does not require that the situation of coercion persists, similar problems may arise in case of adults.

Although these situations would typically be regarded as cases of incitement, they will have to be classified as trafficking in human beings pursuant to the Directive. This will also result in extending criminal liability since the intended criminal activities do not actually have to be carried out. Finally, the minimum maximum penalty of ten years in the case of recruiting a child seems too high, since the statutory penalties for the intended crimes that the latter is supposed to commit may be much lower.

\section{2. "Horizontal" coherence - consistency with other EU legislative acts}

The efforts to harmonise the Member States' criminal law provisions against trafficking in human beings conform - generally speaking - to the other measures taken by the Union. ${ }^{26}$ However, this Directive is not in line with at least one other EU instrument. According to Art. 2 (1) and (3), the Member States shall take the necessary measures to ensure that the intentional recruitment of a child for the purpose of any form of sexual exploitation is punishable (and pursuant to Art. 2 (5) no means of coercion must be used in this case). The Directive on combating the sexual abuse and sexual exploitation of children and child pornography, ${ }^{27}$ however, only calls for penalising the recruitment of a child for the participation in child prostitution, i. e. for one particularly severe form of sexual exploitation. But the inconsistencies do not end at this point: although the two Directives partly cover the same behaviour they provide for different minimum maximum penalties. While the narrower Directive on combating child pornography establishes a minimum maximum penalty of 8 or 5 years respectively, Art. 4 (2) (a) of the broader Directive on combating trafficking in human beings requires a minimum maximum penalty of 10 years since children are regarded as particularly vulnerable victims. It appears contradictory that the rather general provision embodied in the Directive on combating trafficking in human beings should provide for a higher minimum maximum penalty than the Directive which was specifically designed to harmonise the national provisions on the sexual exploitation of children.

\footnotetext{
${ }^{26}$ ECPI, ZIS 2009, 707, 709 and EuCLR 2011, 86, 91.

${ }^{27}$ Directive 2011/93/EU, OJ 2011 No. L 335, p. 1.
} 


\section{Conclusions and proposals for amendments}

This Directive satisfies in many respects the requirements for a reasonable criminal policy. The aim of the Directive to fight trafficking in human beings is legitimate and requires - at least generally speaking - the recourse to criminal law sanctions at the European level. However, it would be highly desirable if the EU legislator were not to opt for harmonising the particularly sensitive area of criminal law without firstly assessing the scope of the problem on the basis of a statistically significant empirical analysis of how many people are subject to exploitative practices each year in the Union and without secondly showing how the national criminal justice systems fail to address these problems. The European institutions should also improve their statement of the reasons for the adoption of new legal instruments. In many aspects, their motifs, which are necessary to test the instrument against the principles of proportionality, subsidiarity and coherence, are not mentioned at all or not in their entirety. The legitimacy of the Directive is in many aspects reasoned by the mere statement that trafficking in human beings is a particularly serious crime without distinguishing between the various forms of behaviour that fall under the definition. On the basis of the above evaluation, the following alterations or improvements appear particularly advisable:

\section{A more precise wording of Art. 2 (2) of the Directive}

The definition of a position of vulnerability in Art. 2 (2) ("no real or acceptable alternative") should be modified to make clear that the Directive applies an objective standard for determining whether or not the person concerned did have acceptable alternatives. While the English text does not necessarily create a need for such an amendment, the German version ("für sie annehmbar") seems to differ from the English text in this regard. Cf. supra V.1.

Likewise, the Directive should define the term "abuse of power" more closely. This term equally expresses a certain divide in power, but does not take recourse to the (individual) vulnerability of the victim but to the (individual) strength of the perpetrator. This might be expressed by the following definition: "Abuse of power means that due to his or her sex, physical or mental condition, economic situation, availability of weapons, dangerous objects or other means of technical equipment, superiority in numbers or other circumstances, the perpetrator has gained a significant position of superiority over the victim which the perpetrator uses for the purpose of preventing or breaking resistance and to facilitate the achievement of the perpetrator's objectives against the victim." Cf. supra V.1.

In order to phrase Art. 2 (2) even more precisely and to clarify that children will under usual circumstances find themselves in a position of vulnerability, the following should be added to the provision: "Such a situation might arise from the age of the victim, the victim's physical or mental development, the victim's health condition, an apparent and severe financial distress or a pregnancy. Cf. supra V.1. 


\section{A more precise wording of Art. 2 (3) of the Directive}

Art. 2 (3) of the Directive should be formulated more restrictively. This provision should only apply to "the exploitation of coerced criminal activities". This would reflect a typical aspect of trafficking in human being and reduce the danger of incompatibilities with existing national criminal law provisions on participation in crimes. Cf. supra VII.1.

\section{A more precise wording of Art. 2 (4) of the Directive}

Art. 2 (4) of the Directive should be amended as follows: “... shall be irrelevant where any of the means set forth in paragraph 1 have been used and continue to influence the decision of the victim." Cf. supra II.2.

\section{Deleting Art. 2 (5) of the Directive}

Art. 2 (5) of the Directive should be deleted. There are only very few conceivable cases in which a child would not be in a position of vulnerability due to its age (cf. the proposed amendment to Art. 2 (2)). In these cases, the use of a means of coercion must not be omitted. Otherwise, the elements of the crime would no longer reflect the particularly typical conduct of trafficking in human beings. Conflicts with the laws of participation in crimes as embodied in the national criminal justice systems may also be avoided or mitigated. Cf. supra II.2.

\section{Amending the minimum maximum penalties}

Apart from general objections against the use of minimum maximum penalties ${ }^{28}$, the minimum maximum penalty for cases of recruitment in the Directive should be reduced. This would reflect that the act of recruitment takes place before the victim's rights are actually infringed; thus the perpetrator does not appear to be as blameworthy as in other cases and does not deserve such a harsh punishment. The contradiction to Art. 4 (5) of the Directive combating child pornography could also be resolved by lowering the minimum maximum penalty for cases of recruitment. Cf. supra III.1., IV. and VII.2.

In order to ensure a punishment in accordance with the principle of guilt, the Directive should distinguish between the profiteers of a crime and the helpers at the level of criminal sanctions. The EU legislator should amend Art. 4 (1) of the Directive in order to allow Member States to lower the minimum maximum penalties for less serious cases. This could include the alternatives of exchanging or transferring the control over persons if a means of coercion is not used directly against the victim. Cf. supra IV.

\footnotetext{
${ }^{28}$ Satzger, International and European Criminal Law, Munich 2012, § 7 para. 45; ECPI, ZIS 2009, 707, 709 and EuCLR 2011, 86, 91.
} 


\section{Amending the minimum maximum penalties for severe cases}

Art. 4 (2) (a) should only apply to cases in which the victim "was particularly vulnerable and the perpetrator used a means of coercion pursuant to paragraph 1." This would prevent every ordinary case of vulnerability from amounting to a particularly severe case at the same time. The clarification according to which human trafficking of children must be considered a severe case would be redundant taking into account the amendment to Art. 2 (2) proposed above. Such an amendment would also avoid contradictions to the Directive combating child pornography: in cases where an additional means of coercion is used, it seems legitimate to raise the level of punishment. Cf. supra IV. and VII.2.

Art. 4 (2) (d) should apply only to harm done to the victim's health. The EU legislator should also explain when such bodily harm is particularly serious. This may, for example, be the case where the damage to the victim's health is long-lasting or has grave consequences for their physical integrity, requires long treatment, results in a lasting disability or annihilates or reduces the victim's ability to work. A definition of this kind would resolve the conflict with the principle of definiteness. Cf. supra IV. and V.2. 